\title{
Inflammation in pulmonary arterial hypertension
}

\author{
P. Dorfmüller, F. Perros, K. Balabanian, M. Humbert
}

Inflammation in pulmonary arterial hypertension. P. Dorfmüller, F. Perros, K. Balabanian, M. Humbert. (C) ERS Journals Ltd 2003.

ABSTRACT: Inflammatory mechanisms appear to play a significant role in some types of pulmonary hypertension (PH), including monocrotaline-induced $\mathrm{PH}$ in rats and pulmonary arterial hypertension of various origins in humans, such as connective tissue diseases (scleroderma, systemic lupus erythematosus, mixed connective disease), human immunodeficiency virus infection, or plasma cell dyscrasia with polyneuropathy, organomegaly, endocrinopathy, monoclonal (M) protein and skin changes (POEMS) syndrome.

Interestingly, some patients with severe pulmonary arterial hypertension associated with systemic lupus erythematosus have experienced significant improvements with immunosuppressive therapy, emphasising the relevance of inflammation in a subset of patients presenting with $\mathrm{PH}$. Patients with primary $\mathrm{PH}(\mathrm{PPH})$ also have some immunological disturbances, suggesting a possible role for inflammation in the pathophysiology of this disease. A subset of PPH patients have been shown to have circulating autoantibodies, including antinuclear antibodies, as well as elevated circulating levels of the pro-infammatory cytokines, interleukins $\mathbf{- 1}$ and $\mathbf{- 6}$. Lung histology has also revealed inflammatory infiltrates in the range of plexiform lesions in patients displaying severe $\mathrm{PPH}$, as well as an increased expression of the chemokines regulated upon activation, normal T-cell expressed and secreted (RANTES) and fractalkine.

Further analysis of the role of inflammatory mechanisms is necessary to understand whether this component of the disease is relevant to its pathophysiology.

Eur Respir J 2003; 22: 358-363.
Centre for Pulmonary Vascular Diseases UPRES EA 2705, Dept of Respiratory and Intensive Care Medicine, South Paris Cytokine Institute, Antoine Béclère Hospital, Assistance Publique-Hôpitaux de Paris, South Paris University, Clamart, France.

Correspondence: M. Humbert, Dept of Respiratory and Intensive Care Medicine, Antoine Béclère Hospital, 157 rue de la Porte de Trivaux, 92140 Clamart, France.

Fax: 33146303824

E-mail: humbert@ipsc.u-psud.fr

Keywords: Chemokines, connective tissue disease, endothelial cells, inflammatory infiltrate, pulmonary arterial hypertension, monocrotaline

Received: April 72003

Accepted: April 162003

This group has been supported in part by grants from Legs Poix, Université Paris-Sud, Association Française contre les Myopathies and Institut National de la Santé et de la Recherche Médicale.
Pulmonary arterial hypertension $(\mathrm{PAH})$ is characterised by an elevated mean pulmonary artery pressure $\geqslant 25 \mathrm{mmHg}$ at rest, with a normal pulmonary artery wedge pressure. This severe condition leads to progressive right heart failure and ultimately death [1]. The Evian Classification reflects recent advances in the understanding of pulmonary hypertensive diseases, and recognises the similarity between "unexplained" pulmonary hypertension (PH) (primary $\mathrm{PH}(\mathrm{PPH})$ ) and $\mathrm{PAH}$ of certain known aetiologies, such as collagen vascular diseases, human immunodeficiency virus (HIV) infection, portal hypertension, congenital systemic-to-pulmonary shunts and anorexigen exposure [2].

PAH results from chronic obstruction of small pulmonary arteries, which is due, at least in part, to endothelial and vascular smooth muscle cell dysfunction and proliferation [3]. The recent discovery that a significant proportion of patients with familial, as well as sporadic, $\mathrm{PPH}$ have germline mutations of genes encoding receptor members of the transforming growth factor (TGF)- $\beta$ family (bone morphogenetic protein receptor-II and activin receptor-like kinase-1), suggests that dysfunctional TGF- $\beta$ signalling could lead to an abnormal proliferation of pulmonary vascular cells [4, 5]. Although these major advances have improved the understanding of $\mathrm{PAH}$, more information is needed to evaluate the possible involvement of additional factors in its pathogenesis. The authors and others have recently proposed that inflammatory mechanisms could play a part in the genesis or progression of PAH. This review will analyse recent information supporting the relevance of inflammation in animal models [6, 7] and patients displaying $\mathrm{PH}$.

\section{The role of inflammation and autoimmunity in pulmonary arterial hypertension}

\section{Pulmonary arterial hypertension in connective tissue diseases}

PAH is a common complication of systemic inflammatory conditions, such as scleroderma and systemic lupus erythematosus. Pulmonary arterial lesions in the lungs of

Previous articles in this Series: No. 1: Humbert M, Trembath RC. Genetics of pulmonary hypertension: from bench to beside. Eur Respir J 2002; 20: 741-749. No. 2: Galiè N, Manes A, Branzi A. The new clinical trials on pharmacological treatment in pulmonary arterial hypertension. Eur Respir J 2002; 20: 1037-1049. No. 3: Chemla D, Castelain V, Hervé P, Lecarpentier Y, Brimioulle S. Haemodynamic evaluation of pulmonary hypertension. Eur Respir J 2002; 20: 1314-1331. No. 4: Eddahibi S, Morrell N, d'Ortho M-P, Naeije R, Adnot S. Pathobiology of pulmonary arterial hypertension. Eur Respir J 2002; 20: 1559-1572. No. 5: Widlitz A, Barst RJ. Pulmonary arterial hypertension in children. Eur Respir J 2003; 21: 155-176. No. 6: Moloney ED, Evans TW. Pathophysiology and pharmacological treatment of pulmonary hypertension in acute respiratory distress syndrome. Eur Respir J 2003; 21: 720-727. No. 7: Barberà JA, Peinado VI, Santos S. Pulmonary hypertension in chronic obstructive pulmonary disease. Eur Respir J 2003; 21: 892-905. 
patients suffering from connective tissue diseases (CTD) with isolated PH are often similar to those found in lungs displaying PPH, including plexogenic arteriopathy. Resemblance in pathological anatomy may suggest an identical pathophysiology. Besides medial hypertrophy, intimal "onion bulb" lesions and characteristic glomoid-like plexiform lesions, Cool et al. [8] have reported that in patients with scleroderma-related PH, mononuclear inflammatory cells surround vascular sites of plexiform growth, but not uninvolved vessels or extravascular lung structures. In addition, TUDER et al. [9] were the first to identify inflammatory infiltrates in the range of plexiform lesions in the lungs of patients displaying severe PPH. This common denominator of PPH and PAH associated with CTD underlines a possible role for vascular inflammation in PAH. In in vitro experiments, auto-antibodies from patients with CTD (anti-U1-ribonucleoprotein antibodies, anti-double-stranded deoxyribonucleic acid antibodies) have been shown to induce up-regulation of immuno-active molecules, such as intercellular adhesion molecule-1, endothelial leukocycte adhesion molecule-1 and major histocompatibility complex class II, on human pulmonary endothelial cells, suggesting that such immunitary/inflammatory processes could lead to a proliferative and inflammatory pulmonary vasculopathy [10]. Some studies have reported a significant improvement in PAH associated with CTD after immunosuppressive therapy [11]. However, this clinical observation still needs to be confirmed by large prospective studies (see below).

\section{Disturbances of the immune system can be complicated by pulmonary arterial hypertension}

The course of other immunological disturbances, such as HIV infection [2] or plasma cell dyscrasia with polyneuropathy, organomegaly, endocrinopathy, $\mathbf{M}$ protein and skin changes (POEMS syndrome) [12], can be complicated with significant PAH. Inflammatory action in the range of affected vessels has been observed in HIV patients with PAH, although development of severe PAH seems to be unrelated to the degree of immune deficiency [8]. Nevertheless, in a previous study it was demonstrated that a group of HIV patients displaying PAH had significantly higher auto-antibody levels than a matched HIV non-PAH control group [13]. This could indicate a role for a complicating auto-immunity status in the evolution of some seropositive patients, triggering the development of PAH and thereby worsening prognosis [14]. Excessive production of immune mediators in the rare POEMS syndrome with $\mathrm{PH}$ has been reported by FEINBERG et al. [15]. Increased baseline levels of tumour necrosing factor (TNF)- $\alpha$, soluble TNF-receptor type I (sTNF-RI), interleukin (IL)-6, interferon gamma, IL-2, soluble IL-2 receptor (sIL-2R) and abnormally low levels of sIL-6R normalised with steroid application and plasmapheresis, with an improvement of disease status. As the interplay of IL-6 and its receptor sIL-6R appears to be relevant to the pathogenic manifestations of POEMS syndrome with $\mathrm{PH}$, it is remarkable that excessive IL-1 and - 6 serum levels have been described in pure $\mathrm{PPH}$, as compared with $\mathrm{PH}$ secondary to chronic obstructive pulmonary disease [16]. The authors have recently reported an exaggerated production of $\mathrm{CX} 3 \mathrm{C}$ chemokine fractalkine (FKN) and an increased interaction with its receptor, CX3C-R1, in the lungs of patients suffering from severe PPH [17].

\section{Primary pulmonary hypertension patients show a pattern of autoimmunity and inflammation}

A large proportion of "pure" PPH patients without immunodeficiency or other associated systemic diseases
Table 1. - Plasma concentrations of soluble markers in patients with pulmonary arterial hypertension $(\mathrm{PAH})$ and controls

\begin{tabular}{lccl}
\hline Molecules & PAH & Controls & p-values \\
\hline Subjects n & 29 & 26 & \\
$\mathrm{sCD} 25 \mu \mathrm{g} \cdot \mathrm{mL}^{-1}$ & $2.8 \pm 0.3$ & $1.9 \pm 0.2$ & 0.025 \\
$\mathrm{sP}-\mathrm{sel} \mu \mathrm{g} \cdot \mathrm{mL}^{-1}$ & $66.6 \pm 5.4$ & $52.2 \pm 4.3$ & 0.04 \\
$\mathrm{sE}-\mathrm{sel} \mathrm{ng} \cdot \mathrm{mL}^{-1}$ & $79.5 \pm 6.9$ & $37.3 \pm 3.6$ & 0.0001 \\
$\mathrm{sICAM}-1 \mathrm{ng} \cdot \mathrm{mL}^{-1}$ & $370.8 \pm 27.3$ & $212.6 \pm 11.9$ & 0.0001 \\
$\mathrm{sVCAM}-1 \mu \mathrm{g} \cdot \mathrm{mL}^{-1}$ & $2.5 \pm 0.1$ & $1.3 \pm 0.1$ & 0.0001 \\
$\mathrm{sIL}-6 \mathrm{pg} \cdot \mathrm{mL}^{-1}$ & $13.8 \pm 6.0$ & $3.7 \pm 1.3$ & 0.0001 \\
$\mathrm{vWF} \mathrm{U} \cdot \mathrm{dL}^{-1}$ & $165.6 \pm 14.5$ & $100.2 \pm 7.4$ & 0.0005 \\
\hline
\end{tabular}

Data are presented as mean \pm SE unless otherwise stated. sCD25: soluble CD25; sP-sel: soluble P-selectin; sE-sel: soluble E-selectin; sICAM-1: soluble ICAM-1; sVCAM-1: soluble VCAM-1; sIL-6: soluble interleukin-6; vWF: von Willebrand Factor. Table modified from [17].

have evidence of autoimmunity and/or active inflammation, including detectable levels of circulating antinuclear antibodies [18], elevated serum levels of the pro-inflammatory cytokines IL-1 and -6 [16], and increased pulmonary expression of platelet-derived growth factor [19] or macrophage inflammatory protein-1 $\alpha$ [20]. For example, anti-fibrillinauto-antibodies (anti-Fbn-1) are commonly found in systemic sclerosis, calcinosis, Raynaud's phenomenon, oesophageal involvement, sclerodactyly, telangiectasia syndrome (CREST) and mixed connective tissue disease. MORSE et al. [21] have reported elevated frequency of anti-Fbn-1 in patient groups of adults with PPH $(93 \%, n=75)$, children with PPH $(84 \%, n=33)$ and patients with appetite suppressant-associated PPH $(67 \%$, $\mathrm{n}=18$ ), as compared with healthy individuals. In addition, recent data providing evidence for a close association of PPH and autoimmune thyroid disease, such as Grave's disease or Hashimoto-thyreoiditis, has revealed the possibility of an autoimmunitary pathomechanism in PPH [22]. Further evidence supporting the concept of a systemic inflammatory component in PPH was recently given by BALABANIAN et al. [17], who demonstrated significantly increased plasma levels of various inflammatory markers in patients with severe $\mathrm{PPH}$, as compared with normal controls (table 1).

\section{The monocrotaline model}

Pathological changes in lungs of patients displaying PAH do not concern the whole pulmonary arterial tree, but remain restricted to certain levels of the vessel. The classical hypertensive pulmonary arteriopathy concerns overall muscular arteries of $\leqslant 500 \mu \mathrm{m}$ in diameter, corresponding to the subsegmentary arteries and their down-stream colaterals. Different and characteristic lesions, such as isolated medial hypertrophy, concentric intimal fibrosis, in situ thrombosis, pulmonary arteritis and typical plexiform lesions with their glomoid-like exhuberant endothelial cell proliferation, are found [23]. Perivascular inflammatory infiltrates with macrophages and lymphocytes in the range of occlusive lesions can be observed in PAH [9]. Endothelial cell dysfunction with deregulated expression of vasoactive, mitogenic and proinflammatory mediators may be the cause of these changes $[24,25]$. Monocrotaline, a plant-derived toxine, causes endothelial cell injury and subsequently a massive mononuclear infiltration into the perivascular regions of arterioles and musculary arteries when injected into rats. These animals develop severe PH after monocrotaline exposure [26]. Although typical plexiform lesions are not normally found in monocrotaline-induced $\mathrm{PH}$, it is used as a standard model for PAH and PPH. The important role of inflammation in this model has led to several studies focusing on immunosuppressive and 


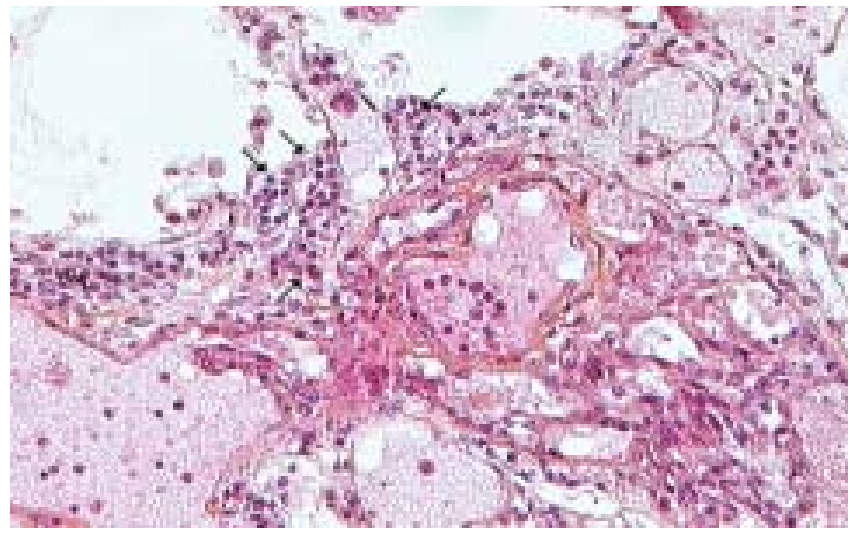

Fig. 1.-Plexiform lesion with strong, mainly lymphocytic (arrows) inflammatory infiltrate in a lung sample of a patient with severe primary pulmonary hypertension.

anti-cytokine treatment (see below), and, therefore, raises the question of how involved inflammatory cascades are in the installation and evolution of PAH lesions in humans.

\section{The role of chemokines in pulmonary arterial hypertension}

Identification of perivascular inflammatory cell infiltrates, comprised of T- and B-lymphocytes and macrophages, has supported the concept that inflammatory cells may play a role in PAH. The involvement of leukocytes, such as macrophages and lymphocytes, in complex lesions of PPH was initially described by TUDER et al. [9]. Recent studies by DORFMÜLLER et al. [27] have confirmed this observation, stressing the possible role of perivascular lymphocytic infiltrates. This inflammatory pattern has been demonstrated in plexiform lesions, as well as in other vascular lesions of PAH-affected lungs (fig. 1).

The role of T-lymphocyte recruitment by chemotactic cytokines in PAH has also been previously evaluated. Leukocyte trafficking involves successive events, including rolling, firm adhesion and extravasation, in response to a chemoattractant gradient that may involve chemokines [28]. Chemokines are soluble, secreted basic proteins that direct the migration of specific subsets of leukocytes [28, 29]. They play a major role in the different steps of leukocyte recruitment, including rolling, activation, adherence and extravasation into the inflammed tissue. The above-mentioned studies by DORFMÜller et al. [27] and BALABANIAN et al. [17] have attempted to analyse those chemokine-dependent mechanisms leading to inflammatory cell recruitment in the lungs of patients displaying PAH. FKN/CX3CL1 is a unique chemokine, since it exists in both a soluble form as a chemotactic protein and in a membrane-anchored form as a cell-adhesion molecule on endothelial cells [30, 31]. Its actions are mediated by CX3CR1, a seven transmembrane receptor that is expressed by monocytes, microglial cells, neurons, natural killer cells, mast cells and subpopulations of T-lymphocytes [32-37]. FKN promotes CX3CR1-expressing leukocyte recruitment, but, unlike other chemokines, it can mediate the rapid-capture, integrin-independent adhesion and activation of circulating CX3CR 1+ leukocytes under high blood flow [38-40]. Several recent studies have reported a polymorphism in CX3CR1 associated with a reduced risk of acute coronary artery disease, suggesting that FKN plays a critical role in monocyte/T-cell recruitment to the vessel wall [41, 42]. The authors were able to demonstrate the following: 1) CX3CR1 was upregulated in circulating CD4+ and CD8+ T-lymphocytes from $\mathrm{PAH}$ patients, as compared with controls; 2) this deregulation of
CX3CR1 expression accounted for the increased sensitivity of these cells to soluble FKN (sFKN) (fig. 2); 3) the abnormal response of T-lymphocytes to FKN was not the mere consequence of $\mathrm{PH}$, as it was not present in patients with $\mathrm{PH}$ secondary to chronic thrombembolic PH (CTEPH); 4) elevated sFKN plasma concentrations were measured in PAH patients, as compared with CTEPH patients and normal controls; 5) lung samples from PAH patients showed an increased FKN messenger ribonucleic acid (mRNA) expression, as compared with controls, and pulmonary artery endothelial cells from PAH patients expressed FKN (fig. 3).

Regulated upon activation, normal T-cell expressed and secreted (RANTES) is an important chemoattractant for monocytes and T-cells [43, 44]. RANTES presumably plays a key role in a number of arterial inflammatory processes, such as glomerulonephritis [45], Kawasaki disease [46] and Takayasu arthritis [47]. In addition, successful antagonisation of RANTES has been reported in animal models of inflammatory disease [48-50]. RANTES may also play an indirect role in PAH through the induction of endothelinconverting enzyme-1 and endothelin-1, a potent endotheliumderived factor with strong vasoconstrictive and mitogenic action [51]. In their recent work, DORFMÜLLER et al. [27] have found new evidence for a possible involvement of this potent mediator in the evolution of PAH. Experiments on patients and healthy controls showed the following: 1) RANTES mRNA was detected by competitive reverse transcriptasepolmerase chain reaction in lung samples from all $\mathrm{PAH}$ patients and controls; 2) the number of RANTES mRNA copies was significantly elevated in the lungs of PAH patients as compared with controls (fig. 4); and 3) endothelial cells were the major source of RANTES, identified by in situ hybridisation and immunohistochemistry in PAH lung samples (fig. 5) [27].

\section{Inflammation in pulmonary arterial hypertension: therapy}

\section{Immunosupressants in the therapy of pulmonary arterial hypertension}

The effectiveness of corticosteroids and immunosuppressants in the treatement of PAH associated with connective tissue disorders has been discussed previously. In the absence of a larger placebo-controlled study, evaluations about efficacy of such treatment rely on case reports and observations in smaller groups. Nevertheless, many of these publications have reported an improvement after treatment, usually with a combination of immunosuppressants and corticoids $[11,52]$. Interestingly, convincing results with decreasing mean pulmonary arterial pressures of $<28 \mathrm{mmHg}$ have been frequently reported in patients suffering from systemic lupus erythematosus [53, 54]. Conversely, treatment in patients with systemic sclerosis seems to be less effective on PH, suggesting that different mechanisms may be involved in the pathogenesis of PH secondary to scleroderma. Usually, corticosteroids associated with immunosuppressants, such as cyclophosphamide in bolus infusion, seem to be the most effective treatment. However, immunosuppressive protocols vary from one study to another and comparison is difficult. Lastly, there can be difficulties in evaluating the effects of immunosuppressive therapy alone because of the frequent use of vasodilator therapy [11]. In conclusion, immunosuppressants should be considered for patients with CTD and PAH, with the important exception of scleroderma. Here, strict clinical and haemodynamical criteria are necessary to evaluate the efficacy of such a treatment. If there is no clinical and haemodynamical improvement after 3-6 months of therapy 

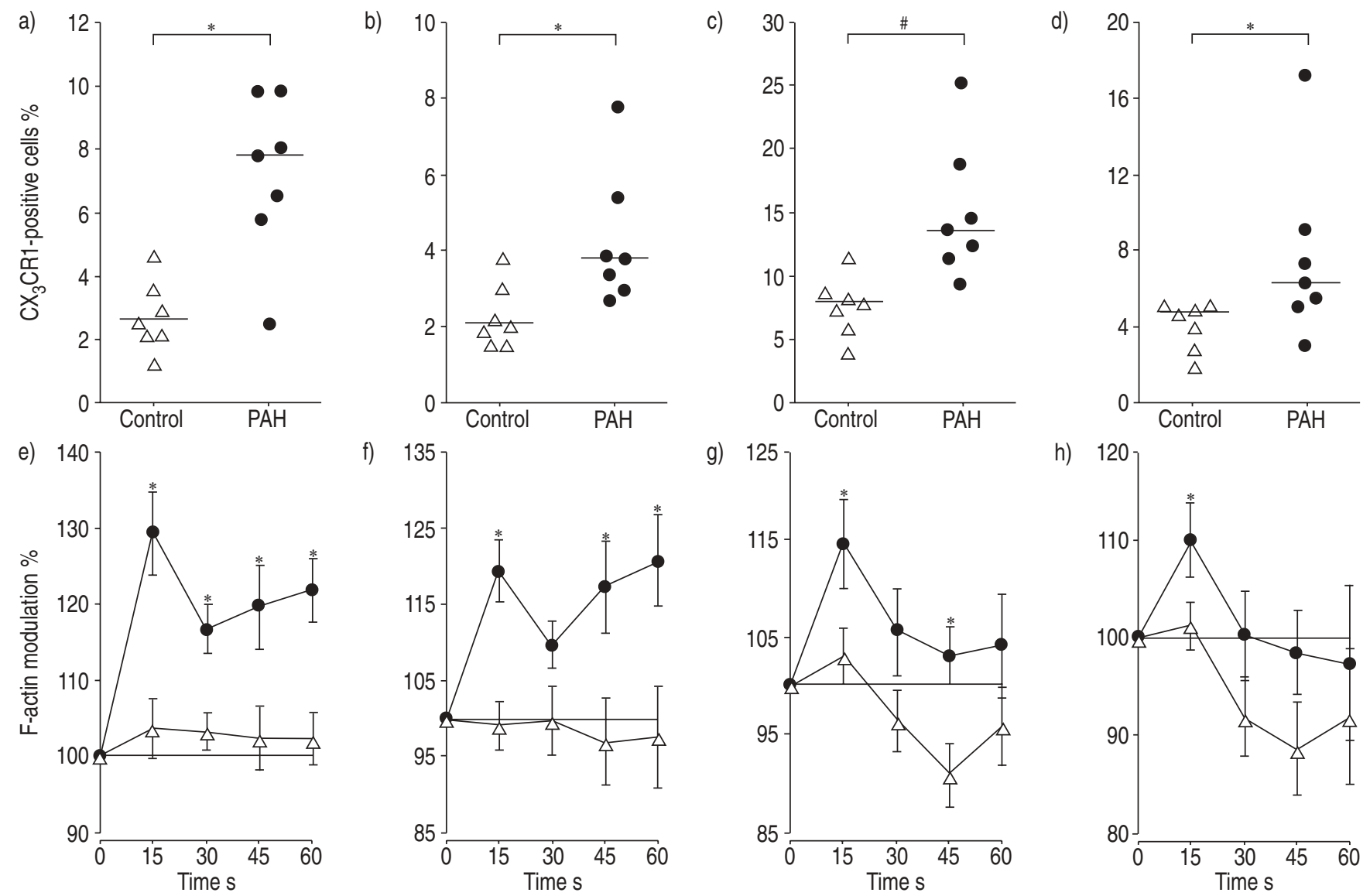

Fig. 2. $-\mathrm{a}-\mathrm{d})$ Expression and function of $\mathrm{CX}_{3} \mathrm{CR} 1$ by $\mathrm{T}$-lymphocytes from pulmonary arterial hypertension (PAH) patients. Expression of $\mathrm{CX}_{3} \mathrm{CR} 1$ was analysed by flow cytometry in memory (CD45RO+) (a and c) and naive (CD45RO-) (b and d) CD4+ and CD8+ T-lymphocytes. Results are expressed as the proportion of labelled cells for each healthy control $(\mathrm{n}=7, \triangle)$ and PAH patient $(\mathrm{n}=7, \mathbf{0})$. $^{*}: \mathrm{p}<0.05$; ${ }^{\#}: \mathrm{p}<0.005$. eh) In the same individuals the function of $\mathrm{CX}_{3} \mathrm{CR} 1$ was tested by monitoring actin polymerisation ( $\bullet$ : PAH patients, $\mathrm{n}=7$; $\triangle$ : healthy controls, $\mathrm{n}=7$ ). Results show the kinetics of actin polymerisation following fractalkine addition, with time. Baseline level, before fractalkine addition, are represented as $100 \%$. *: $\mathrm{p}<0.05$. Error bars show SEM. Horizontal lines show median values. Figure modified from [17].

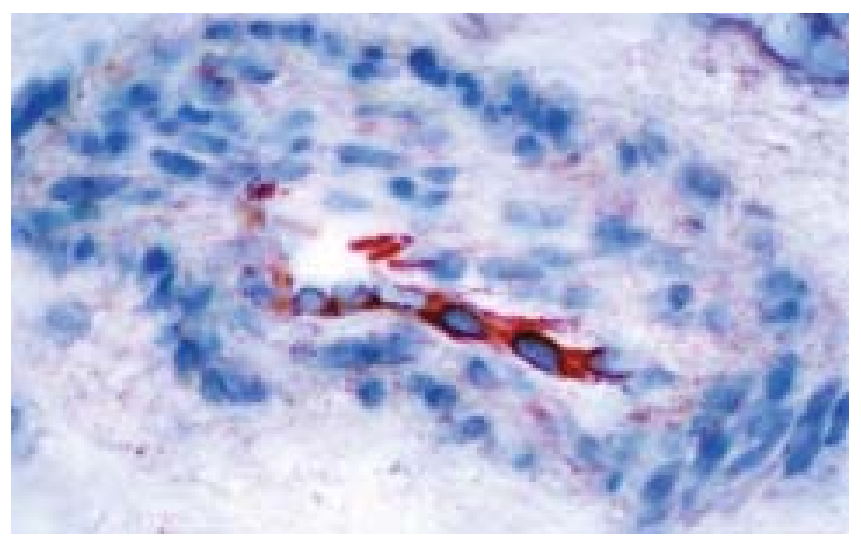

Fig. 3. - Fractalkine protein detected by immunohistochemistry in the endothelium of small muscular pulmonary arteries (lung sample taken at the time of lung transplantation in a patient suffering from severe pulmonary arterial hypertension), endothelial proliferation with obstruction of the vessel and strong endothelial staining. Figure modified from [27].

then treatment should be stopped because of possible complications, including infections and neoplasms.

Recent studies on animal models with induced PH have highlightened two other substances with immunosuppressive

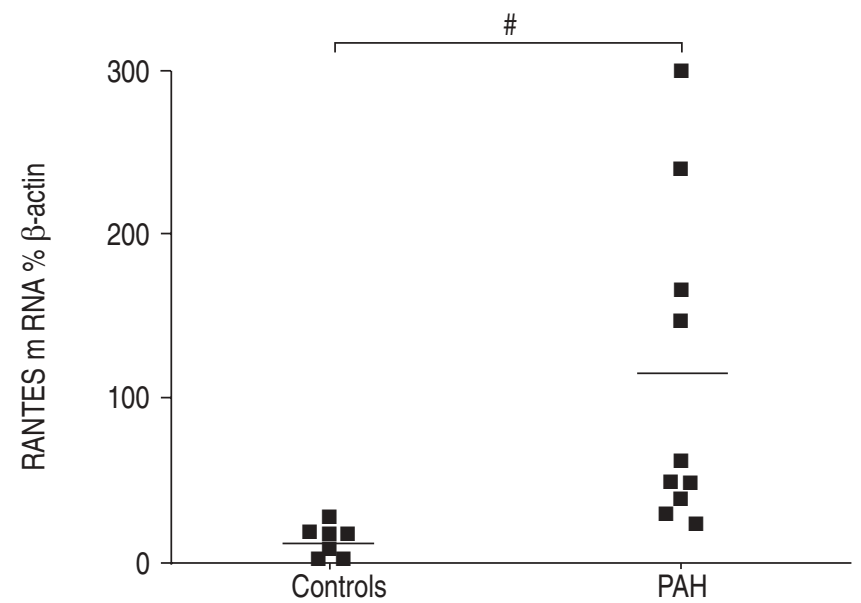

Fig. 4.-Regulated upon activation, normal T-cell expressed and secreted (RANTES) messenger ribonucleic acid (mRNA) expression detected by competitive reverse transcriptase-polymerase chain reaction in lung samples from patients suffering from severe pulmonary arterial hypertension $(\mathrm{PAH})$ and controls. ${ }^{\#}: \mathrm{p}=0.017$. Horizontal lines show mean values. Figure modified from [27].

effects in the treatment of PH. Rapamycin, a macrolide immunosuppressant currently being used in therapy for chronic allograft rejection, and triptolide, a herb used in 


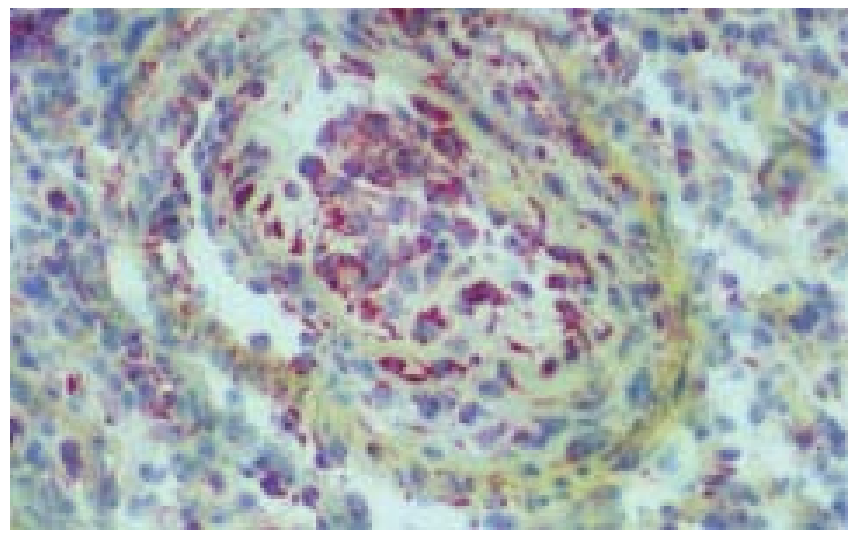

Fig. 5.-Regulated upon activation, normal T-cell expressed and secreted (RANTES) messenger ribonucleic acid expression detected by in situ hybridisation in the endothelium of small muscular pulmonary arteries, and to a lesser extent in perivasular cells (lung sample taken at the time of lung transplantation in a patient suffering from severe pulmonary arterial hypertension), plexiform lesion with endothelial and perivascular staining. Figure modified from [27].

traditional chinese medicine to treat rheumatoid arthritis and other autoimmune diseases, have been tested on rats being pneumectomised and subsequently treated with monocrotaline [26, 55]. Both rapamycin and tryptolide showed significant effects with lower mean pulmonary arterial pressures, as compared with vehicle-treated controls. As a morphological correlate to these findings, a significantly less right ventricular hypertrophy and pulmonary arterial neointimal formation were demonstrated. It is noteworthy that tryptolide shows anti-inflammatory properties by inhibiting $\mathrm{T}$-cell activation at the level of cytokine gene transcription [56].

\section{Anti-cytokine treatment in pulmonary arterial hypertension}

Cytokine antagonists have been mainly tested on the monocrotaline rat model. VoELKEL et al. [6] have studied the role of IL-1, a strong pro-infammatory cytokine, in monocrotaline-induced $\mathrm{PH}$ as compared with chronic hypoxia $\mathrm{PH}$, showing that IL-1 is excessively produced in the lungs of rats treated with monocrotaline. Repeated injections of IL-1 receptor antagonist reduced $\mathrm{PH}$ and right heart hypertrophy in the monocrotaline model but not in the chronic hypoxia model. If studies showing elevated circulating levels of IL-1 and -6 in patients displaying $\mathrm{PPH}$, but not in patients with $\mathrm{PH}$ secondary to COPD are considered, a possible role for mediators of inflammation in some forms of $\mathrm{PH}$ can be assumed [16]. However, the authors are not aware of any studies attempting to evaluate anti-cytokine therapies in $\mathrm{PH}$ patients.

Numerous studies on inflammatory diseases and the effects of anti-cytokine treatment have stressed the importance of such therapeutic alternatives. Animal model experiments with RANTES-receptor antagonists (Met-RANTES), show relevant anti-inflammatory properties in the treatment of chronic allograft nephropathy. In their latest study, SoNG et al. [57] showed that Met-RANTES diminishes the early infiltration and activation of mononuclear cells in grafts of transplanted rat kidneys accompanied by a local decrease of IL-1, -2 and TNF- $\alpha$, as well as RANTES, and thereby reduces the pace of chronic allograft nephropathy. Moreover, recent studies demonstrated the prevention of crescentic glomerulonephritis in animal models by immunoneutralisation of the FKNreceptor CX3CR1 [40]. Considering these studies on FKN and RANTES, and the possible role for these two chemokines in PAH, further studies on animal models should evaluate a possible role for anti-cytokine treatment in this condition.

When assessing these different observations, inflammation and autoimmunity seem to have at least some influence on the evolution of the disease. The frequent association of pulmonary arterial hypertension and well-defined inflammatory conditions, as well as the presence of complicating pulmonary arterial hypertension in autoimmunitary disturbances, indicate a possible role for inflammatory cascades, leading to inflammatory infiltrates and remodeling of the vessel. Latest results from the authors suggest that increased activation of circulating inflammatory cells in affected individuals is a primary event, rather than a pure response to the altered physiological condition of the patient.

\section{References}

1. Rubin LJ. Primary pulmonary hypertension. $N$ Engl $J$ Med 1997; 336: 111-117.

2. Humbert $M$, Nunes $H$, Sitbon O, Parent $P$, Hervé $P$, Simonneau G. Risk factors for pulmonary arterial hypertension. Clin Chest Med 2001; 22: 459-475.

3. Archer S, Rich S. Primary pulmonary hypertension: a vascular biology and translational research "Work in progress". Circulation 2000; 102: 2781-2791.

4. Machado RD, Pauciulo MW, Thomson JR, et al. BMPR2 haploinsufficiency as the inherited molecular mechanism for primary pulmonary hypertension. Am J Hum Genet 2001; 68: 92-102.

5. Trembath RC, Thomson JR, Machado RD, et al. Clinical and molecular genetic features of pulmonary hypertension in patients with hereditary hemorrhagic telangiectasia. $N$ Engl $J$ Med 2001; 345: 325-334.

6. Voelkel NF, Tuder RM, Bridges J, Arend WP. Interleukin-1 receptor antagonist treatment reduces pulmonary hypertension generated in rats by monocrotaline. Am J Respir Cell Mol Biol 1994; 11: 664-675.

7. Kimura H, Kasahara Y, Kurosu K, et al. Alleviation of monocrotaline-induced pulmonary hypertension by antibodies to monocyte chemotactic and activating factor/monocyte chemoattractant protein-1. Lab Invest 1998; 78: 571-581.

8. Cool CD, Kennedy D, Voelkel NF, Tuder RF. Pathogenesis and evolution of plexiform lesions in pulmonary hypertension associated with scleroderma and human immunodeficiency virus infection. Human Pathol 1997; 28: 434442.

9. Tuder RM, Groves B, Badesch DB, Voelkel NF. Exuberant endothelial cell growth and element of inflammation are present in plexiform lesions of pulmonary hypertension. Am J Pathol 1994; 144: 275-285.

10. Okawa-Takatsuji M, Aotsuka S, Fujinami M, Uwatoko S, Kinoshita M, Sumiya M. Up-regulation of intercellular adhesion molecule-1 (ICAM-1), endothelial leucocyte adhesion molecule-1 (ELAM-1) and class II MHC molecules on pulmonary artery endothelial cells by antibodies against U1ribonucleoprotein. Clin Exp Immunol 1999; 116: 174-180.

11. Sanchez O, Humbert M, Sitbon O, Simonneau G. Treatment of pulmonary hypertension secondary to connective tissue diseases. Thorax 1999; 54: 273-277.

12. Lesprit $\mathrm{P}$, Godeau B, Authier FJ, et al. Pulmonary hypertension in POEMS syndrome: a new feature mediated by cytokines. Am J Respir Crit Care Med 1998; 157: 907-911.

13. Opravil M, Pechere M, Speich R, et al. HIV-associated primary pulmonary hypertension. A case control study. Swiss HIV Cohort Study. Am J Resp Crit Care Med 1997; 155: 990-995.

14. Kopelman RG, Zolla Pazner S. Association of human immunodeficiency virus infection and autoimmune phenomena. Am J Med 1988; 84: 82-88.

15. Feinberg L, Temple D, de Marchena E, Patarca R, Mitrani A. Soluble immune mediators in POEMS syndrome with pulmonary hypertension: case report and review of the literature. Crit Rev Oncog 1999; 10: 293-302. 
16. Humbert M, Monti G, Brenot F, et al. Increased interleukin1 and interleukin-6 serum concentrations in severe primary pulmonary hypertension. Am J Respir Crit Care Med 1995; 151: 1628-1631.

17. Balabanian $\mathrm{K}$, Foussat $\mathrm{A}$, Dorfmüller $\mathrm{P}$, et al. $\mathrm{CX}_{3} \mathrm{C}$ chemokine fractalkine in pulmonary arterial hypertension. Am J Resp Crit Care Med 2002; 165: 1419-1425.

18. Isern RA, Yaneva M, Weiner E, et al. Autoantibodies in patients with primary pulmonary hypertension: association with anti-Ku. Am J Med 1992; 93: 307-312.

19. Humbert M, Monti G, Fartoukh M, et al. Platelet-derived growth factor expression in primary pulmonary hypertension: comparison of HIV seropositive and HIV seronegative patients. Eur Respir J 1998; 11: 554-559.

20. Fartoukh M, Emilie D, Le Gall C, Monti G, Simonneau G, Humbert M. Chemokine MIP-1 $\alpha$ expression in lung biopsies of primary pulmonary hypertension. Chest 1998; 114: 5051.

21. Morse JH, Antohi S, Kasturi K, et al. Fine specificity of antifibrillin-1 autoantibodies in primary pulmonary hypertension syndrome. Scand J Immunol 2000; 51: 607-611.

22. Chu JW, Kao PN, Faul JL, Doyle RL. High Prevalence of autoimmune thyroid disease in pulmonary arterial hypertension. Chest 2002; 122: 1668-1673.

23. Pietra GG. The pathology of primary pulmonary hypertension. In: Rubin L, Rich S, eds. Primary pulmonary hypertension. New York, Marcel Dekker, 1997; pp. 19-61.

24. Loscalzo J. Endothelial dysfunction in pulmonary hypertension. N Engl J Med 1992; 327: 117-119.

25. Lopes AA, Maeda NY, Goncalves RC, Bydlowski SP. Endothelial cell dysfunction correlates differentially with survival in primary and secondary pulmonary hypertension. Am Heart J 2000; 139: 618-623.

26. Nishimura T, Faul JL, Berry GJ, Veve I, Pearl RG, Kao PN. 40-O-(2-Hydroxyethyl)- rapamycin attenuates pulmonary arterial hypertension and neointimal formation in rats. Am J Resp Crit Care Med 2001; 163: 498-502.

27. Dorfmüller P, Zarka V, Durand-Gasselin I, et al. Chemokine RANTES in severe pulmonary arterial hypertension. Am J Resp Crit Care Med 2002; 165: 534-539.

28. Springer TA. Traffic signals for lymphocyte recirculation and leucocyte emigration: the multistep paradigm. Cell 1994; 76: $301-314$

29. Zlotnik A, Yoshie O. Chemokines: a new classification system and their role in immunity. Immunity 2000; 12: 121-127.

30. Bazan JF, Bacon KB, Hardiman G, et al. A new class of membrane-bound chemokine with a $\mathrm{CX}_{3} \mathrm{C}$ motif. Nature 1997; 385: 840-844.

31. Papadopoulos EJ, Sassetti C, Saeki H, et al. Fractalkine, a CX3C chemokine, is expressed by dendritic cells and is upregulated upon dendritic cell maturation. Eur J Immunol 1999; 29: 2551-2559.

32. Foussat A, Coulomb-Lhermine A, Gosling J, et al. Fractalkine receptor expression by $\mathrm{T}$ lymphocyte subpopulations and in vivo production of fractalkine in human. Eur J Immunol 2000; 30: 87-97.

33. Harrison JK, Jiang $\mathrm{Y}$, Chen $\mathrm{S}$, et al. Role for neuronally derived fractalkine in mediating interactions between neurons and CX3CR1-expressing microglia. Proc Natl Acad Sci USA 1998; 95: 10896-10910.

34. Imai $\mathrm{T}$, Hieshima $\mathrm{K}$, Haskell $\mathrm{C}$, et al. Identification and molecular characterization of fractalkine receptor $\mathrm{CX}_{3} \mathrm{CR} 1$, which mediates both leukocyte migration and adhesion. Cell 1997; 91: 521-530.

35. Combadiere C, Salzwedel K, Smith ED, Tiffany HL, Berger EA, Murphy PM. Identification of CX3CR1. J Biol Chem 1998; 273: 23799-23804.

36. Papadopoulos EJ, Fitzhugh DJ, Tkaczyk C, et al. Mast cells migrate, but do not degranulate, in response to fractalkine, a membrane-bound chemokine expressed constitutively in diverse cells of the skin. Eur J Immunol 2000; 30: 2355-2361.

37. Fraticelli $\mathrm{P}$, Sironi $\mathrm{M}$, Bianchi $\mathrm{G}$, et al. Fractalkine
(CX3CL1) as an amplification circuit of polarized Th1 responses. J Clin Invest 2001; 107: 1173-1181.

38. Haskell CA, Cleary MD, Charo IF. Molecular uncoupling of fractalkine-mediated cell adhesion and signal transduction. J Biol Chem 1999; 274: 10053-10058.

39. Fong AM, Robinson LA, Steeber DA, et al. Fractalkine and $\mathrm{CX}_{3} \mathrm{CR} 1$ mediate a novel mechanism of leukocyte capture, firm adhesion, and activation under physiologic flow. $J$ Exp Med 1998; 188: 1413-1419.

40. Feng L, Chen S, Garcia GE, et al. Prevention of crescentic glomerulonephritis by immunoneutralization of the fractalkine receptor CX3CR1. Kidney Int 1999; 56: 612-620.

41. Moatti D, Faure S, Fumeron F, et al. Polymorphism in the fractalkine receptor $\mathrm{CX} 3 \mathrm{CR} 1$ as a genetic risk factor for coronary artery disease. Blood 2001; 97: 1925-1928.

42. McDermott DH, Halcox JP, Schenke WH, et al. Association between polymorphism in the chemokine receptor CX3CR1 and coronary vascular endothelial dysfunction and atherosclerosis. Circ Res 2001; 89: 401-407.

43. Luster AD. Chemokines - chemotactic cytokines that mediate inflammation. $N$ Engl $J$ Med 1998; 338: 436-445.

44. Schall T, Bacon K, Toy K, Goeddel D. Selective attraction of monocytes and T lymphocytes of the memory phenotype by cytokine RANTES. Nature 1998; 347: 669-671.

45. Cockwell P, Howie AJ, Adu D, Savage CO. In situ analysis of C-C chemokine mRNA in human glomerulonephritis. Kidney Int 1998; 54: 827-836.

46. Wong M, Silverman ED, Fish EN. Evidence for RANTES, monocyte chemotactic protein-1, and macrophage inflammatory protein-1 beta expression in Kawasaki disease. J Rheumatol 1997; 24: 1179-1185.

47. Noris M, Daina E, Gamba S, Bonazzola S, Remuzzi G. Interleukin-6 and RANTES in Takayasu arteritis: a guide for therapeutic decisions? Circulation 1999; 100: 55-60.

48. Chen $\mathrm{S}$, Bacon $\mathrm{KB}$, Li L, et al. In vivo inhibition of $\mathrm{CC}$ and $\mathrm{CX} 3 \mathrm{C}$ chemokine-induced leukocyte infiltration and attenuation of glomerulonephritis in Wistar-Kyoto (WKY) rats by vMIP-II. J Exp Med 1998; 188: 193-198.

49. Liang M, Mallari C, Rosser M, et al. Identification and characterization of a potent, selective and orally active antagonist of the CC chemokine receptor-1. J Biol Chem 2000; 275: 19000-19008.

50. Grone HJ, Weber C, Weber KS, et al. 1Met-RANTES reduces vascular and tubular damage during acute renal transplant rejection: blocking monocyte arrest and recruitment. FASEB J 1999; 13: 1371-1383.

51. Molet S, Furukawa K, Maghazechi A, Hamid Q, Giaid A. Chemokine- and cytokine-induced expression of endothelin 1 and endothelin-converting enzyme 1 in endothelial cells. J Allergy Clin Immunol 2000; 105: 333-338.

52. Bellotto F, Chiavacci P, Laveder F, Angelini A, Thiene G, Marcolongo R. Effective immunosuppressive therapy in a patient with primary pulmonary hypertension. Thorax 1999; 54: $372-374$.

53. Karmochkine M, Wechsler B, Godeau P. Improvement of severe pulmonary hypertension in a patient with systemic lupus erythematosus. Ann Rheum Dis 1996; 55: 561-562.

54. Morelli S, Giordano M, De Marzio P. Pulmonary arterial hypertension responsive to immunosuppressive therapy in systemic lupus erythematosus. Lupus 1993; 2: 367-369.

55. Faul JL, Nishimura T, Berry GJ, Benson GV, Pearl RG, Kao PN. Triptolide attenuates pulmonary arterial hypertension and neointimal formation in rats. Am J Resp Crit Care Med 2000; 162: 2252-2258.

56. Qiu D, Zhao G, Aoki Y, et al. Immunosuppressant PG490 (triptolide) inhibits T-cell interleukin-2 expression at the level of purine-box/nuclear factor of activated T-cells and NFkappaB transcriptional activation. J Biol Chem 1999; 274: 13443-13450.

57. Song E, Zou H, Yao Y, et al. Early application of MetRANTES ameliorates chronic allograft nephropathy. Kidney Int 2002; 61: 676-685. 